\title{
Impact of Tangible and Intangible Rewards on Organizational Effectiveness: A Mediating Role of Organizational Citizenship Behaviour
}

\author{
Mohammed Hameed* \\ Department of Business Management \\ Ali Hassan Haraj \\ Department of Business Management \\ Anas Salman Alabboodi \\ $\mathrm{PhD}$, Marketing Department, Putra Business School, Malaysia
}

\begin{abstract}
The current study seeks to analyze the impact of the tangible and intangible rewards on organizational effectiveness with the mediating role of organizational citizenship behavior. The study utilized a quantitative research design for that the data was collected using a structured questionnaire. The sample size was 342 . The study framework had 4 constructs namely tangible rewards, intangible rewards, organizational citizenship behavior, and organizational effectiveness. Two of the variables (tangible and intangible rewards) were independent variables, organizational effectiveness was dependent variable and organizational citizenship behavior was mediating variables. All the latent construct was measured using multi items based on 5 point Likert scales from 1 strongly disagree to 5 strongly disagree. The data collection instrument was developed referring to past researches done on the seminal researches. Structural Equation Modelling was used to analyze the data. The results suggested the significant relationship of tangible and intangible rewards with organizational effectiveness directly and through the mediation of organizational citizenship behavior.
\end{abstract}

Keywords: Tangible rewards; Intangible rewards; Organizational effectiveness; Organizational citizenship behaviour.

\section{(9) (i) CC BY: Creative Commons Attribution License 4.0}

\section{Introduction}

Organizations tend to compete on the basis of their human resources, therefore; currently, human resource is considered as the most effective and important resource of the organization that enables them to gain a competitive advantage (Alsakarneh et al., 2018). However; there are different methods and measures used in order to analyse the performance of the employees which able to offer rewards whether they are tangible or intangible (Yousaf et al., 2015). It is being done in the private or public sector as well because the main purpose of these features is to motivate the employees that enable them to contribute towards organizational effectiveness and efficiency as well. However; a large number of organizations is realized that rewards are the best strategy that will help their employee towards performance and contribute to the organizational effectiveness (Day et al., 2016). It is also the responsibility of the organization to focus upon the development of organizational strategies that are for the reward system and performance evaluation otherwise they will have to face the difficulties to maintain their effectiveness in the market through employee productivity.

It is evident that many organizations are failed in bringing the organizational effectiveness because organizational culture is not productive enough to compel employees to develop efficiency and productivity that contribute towards the organizational effectiveness. Those organizations are highly successful that focuses upon development and appreciation of their employee's efforts considerably (Edirisooriyaa, 2015). For that purpose; it is required to develop the effective reward system that illustrates organizational mindset and enable their employees to facilitate learning and productivity. In this way; performance appraisal or evaluation system should be effective key success factor along with the performance indicators should be fine adequately so the employees are able to meet the expectations and they should be aware of the organization strategy regarding the rewards. Rewards are considered by the employees as the motivational factor that brings innovation and energy in their abilities and performance as well that will increase the organizational effectiveness through productivity and efficiency as well Pratheepkanth (2016).

Employees of the organization are required to perform and act accordingly with the help of managers in order to make the organization effective but it is difficult that organizations are failed to comply with the policies and performance standards to meet the organization's expectations. It is evident that organizations are the main culprit to develop equality among the employees in distributing the rewards whether in the tangible or intangible way Kwenin et al. (2017). Organizations do not consider the employee's efforts towards the efficiency and effectiveness that creates issues for them that restrict them towards the development and reduces their motivation as well. It is rather difficult for the organization to manage the employees and bring the rewards system effective that organization flourish in their business challenges and generate profit that ultimately brings the employees efforts recognized and offer them rewards on the basis of performance (Edirisooriyaa, 2015). 
It is also argued that organizational citizenship behavior is the most important element that increases the effectiveness of the organization because it is a kind of responsibility that individual offer to the organization by providing services other than the contractual services. The current study is being associated with Iraq and it is considered that Iraq is a developing economy after the politics change the regime in the recent past and the long waited war ended that increase the rehabilitation phase from the part of the government to develop the rules and regulation for the societies and corporate sector. Therefore; it is necessary to conduct the study in the context of Iraq in order to analyze the impact of tangible and intangible rewards on organizational effectiveness with the mediating role of organizational citizenship behavior. This study will be effective in the Iraq context because they are developing their economy and rewards will contribute towards the organizational effectiveness.

The past researches suggest that human resources are the most important element for the organization to gain success and effectiveness. Therefore; it is required they should be motivated and their efforts should be acknowledged considerably through the means of intangible or tangible rewards. Those organizations that are successful have developed the best reward system which is directly associated with the performance management of the organization. Therefore; employees are aware of their performance objectives and rewards as well. So, it is required for the organization to develop their strategies to focus upon the employees tangible and intangible rewards that enable them to contribute towards organizational effectiveness.

The current study seeks to analyze the impact of the tangible and intangible rewards on organizational effectiveness with the mediating role of organizational citizenship behavior. It is going to be done in the context of Iraq that is a developing nation after the war restructuring and developing of rules and regulation in the country accordingly. Therefore; it is important to assess how organizations are doing their business and increasing their effectiveness. This will help the corporate sector of Iraq to use the findings of the study and bring the effective reward system in the organization to increase its effectiveness.

\section{Literature Review and Hypotheses Development}

The rewards are associated with the motivational theories that assess the individual requirement regarding the rewards. However; there are different theories such as Maslow Hierarchy of Needs, Expectancy theory, Vroom's theory, McGregor X and Y theory and others considered that employee motivation is being backed with the help of need assessment and it should be analyzed or measured through different tools by the organization and offer them rewards adequately (Antoni et al., 2017). However; it is difficult for the organizations to consider employee satisfaction and motivation through rewards. Majority of the organization have their own system which enables them to assess or analyze the employee's motivation and against them, reward is being given to them. Every researcher that presented the theory of motivation brings the focus upon the meeting the requirement which requires the adequate offering of rewards that includes tangible and intangible in nature that will increase the efficiency and motivation ultimately (Tsede and Kutin, 2015). However; it is difficult for the organization to make every employee satisfied through it. It is the responsibility of the manager or human resource manager to facilitate or cope up with the situation to undertake the grudges of the employees that help them to ensure employee get motivated and contribute in the organizational effectiveness or success.

Organizational effectiveness theory was developed back in 1977 and based upon two approaches first was the goal model and second was the resource acquisition model both models represent about the organizational effectiveness and purpose of both models to facilitate organizational effectiveness through the attainment of goal or development of resource that can lead them towards the desired destination (Kwenin et al., 2017). However; this term of effectiveness is the new addition to the management science but it was having an effective approach towards leading the organization to meet the organizational objectives. It is important that currently, every organization is focusing upon the development of criteria whether they want to lead in the market or follow the pattern of the market. Most of the organizations become efficient and effective as well in order to utilize their resources efficiently and enable their resources to help them for achieving the desired objectives (Kwenin et al., 2017).

\section{Rewards and Organizational Effectiveness}

Rewards are designed in order to meet the employee's expectations and appreciate the effort they put in the attainment of organizational objectives. However; it is highly effective for the employees to get appreciated and rewards are being distributed on the basis of their performance. The organization should link their reward system with the organizational strategies that will become the most effective standard for assigning the rewards to the employees and in this way, it will increase the performance and effectiveness of the organization considerably (Edirisooriyaa, 2015). As far as the organizations are a concern; there should be the best fit of rewards whether it is tangible or intangible to facilitate employee motivation and engage them with the attainment of organizational objectives. Organizational effectiveness is associated with employee performance and increases efficiency through human resources. It is required that organization should consider the employees are the main source of generating the effectiveness and financial profitability because they are the mainstream that faces the challenges and enable the organization to achieve their objectives considerably (Omollo and Oloko, 2015).

Tangible rewards are considered as the best and most motivated feature in the corporate sector internationally while the intangible rewards are the least effective for the employees if they are apart from the tangible aspects as well. However; it differs from the position to position in the organization (Hall-Ellis, 2014). Higher position in the organization focuses upon gaining intangible rather than tangible rewards because it increases their powers and influence in the organization for the decision making. Tangible rewards are considered as the financial rewards that 
are a bonus, increment, cash rewards, and others. While on the other hand; intangible rewards are the promotion, increasing the powers in the organization of the individual, enhancement of job descriptions, training, courses and others. The studies suggested that the best fit of tangible and intangible rewards impacts upon the organizational effectiveness (Tsede and Kutin, 2015). Organizational effectiveness is based upon the organizational development in terms of performance and efficiency for that purpose organizations are required to provide ultimate resources to their human resource to gain these objectives and rewards are the one of the best sources to increase their efficiency and improve the organizational effectiveness.

\section{Rewards and Organizational Citizenship Behaviour}

Organizational citizenship behavior is considered as the individual optional behavior that exceeds the job expectation and provides legitimate support to the organizational process. It is also considered as the duties are being performed without the jurisdiction of the individual with the will or deliberate action to serve the organization (HallEllis, 2014). Organization citizenship behavior has an influence on organizational efficiency and effectiveness. In the successful organization, employees give their time to the job extra other than their allotted time in order to provide commitment and contributing towards the organizational objectives. These features are not being mentioned in the organizational strategies or guidelines but it is evident that these features or individual behavior exist in the organization. Organizations cannot be effective or successful until they are found those employees that are behaving positively towards the organizational performance it shows that they are having citizenship of the organization (Carrdona and Bentler, 2016).

Rewards are being linked with those kinds of commitment and dedication for the employees due to their organizational citizenship behavior. However; usually it is not being measured or evaluated through their performance but it is a behavior which requires acknowledgment from the management that increases the efficiency and organizational performance adequately (Schappe, 2015). Most of the organizations are failed to do so and lack of appreciation result in lack of motivation and citizenship behavior among the employees which required to be focused by the management adequately.

\section{Tangible Rewards and Organizational Effectiveness}

Tangible rewards are considered as the financial rewards that are being given on the basis of performance and a way of motivation among employees. However; most of the organizations in the industry use tangible rewards as the means of motivation and accomplishment towards the organizational goals (Sanhari, 2014). Rewards are being used to increase the employee's efficiency to perform better and increase their effectiveness towards organizational performance. Training and other methods are used to increase the skills and capabilities of the employees to facilitate efficiency which is being regarding through the tangible rewards that meet the employees' financial requirement which is a booster for their efficiency (Antoni et al., 2017; Obaid and Eneizan, 2016a;2016b; Sharif et al., 2018).

Tangible rewards are being used at a certain level for the employees to increase their motivation and loyalty as well, however; it is difficult to say that tangible rewards are directly linked with organizational effectiveness. It can be suggested that organizational effectiveness is having a certain relation with the tangible rewards that offer to the employees on the basis of their performance and somehow it is effective to meet the organizational objectives and contribute towards the organizational effectiveness (Yousaf et al., 2015). Hence it leads to the hypothesis as follows.

H1: Tangible rewards play a significant role in organizational effectiveness.

\section{Intangible Rewards and Organizational Effectiveness}

Intangible rewards are considered as the no- financial rewards that are being given to the employees on the basis of their performance which includes: promotions, training, enhancement of authorities, increased job duties and others. It is evident that higher management seeks to get the intangible rewards which increase their influence and powers adequately (Day et al., 2016), however; middle management considers that the combination of tangible and intangible rewards the best way to increase their motivation; but top management is being facilitated through the intangible rewards and enable them to take decision for the future of organization. Similarly; this feature is also associated with the enhancement of the employee's performance and efficiency (Abdelqader et al., 2018; Terera and Ngirande, 2014).

Organizational effectiveness is also linked with the intangible rewards that are being offered to the employees but it is an appreciation in regards of the employee's commitment and dedication towards the attainment of objectives (Omollo and Oloko, 2015). Research suggests most of the employees prefer to get the intangible rewards to increase their motivation. Hence leading to the following hypothesis.

H2: Intangible rewards play a significant role in organizational effectiveness.

\section{Organizational Citizenship and Organizational Effectiveness}

Citizenship in the organization is based upon the commitment and dedication of the employees towards the organizational objectives and performance. Therefore; it provides the luxury to bring efficiency and effectiveness which is quite adequate and simple but it should be given strength to the employees to facilitate this behavior (Schappe, 2015). However; it is evident that those employees those are having citizenship behavior they are loyal and dedicated towards their jobs and attainment of objectives that are assigned to them considerably. It is indeed necessary that an organization should provide a legitimate environment and culture to promote the working 
environment (Carrdona and Bentler, 2016). The need is to bring specific and adequate policies and procedures that are evident for the development of behavior of the individual to facilitate this organizational citizenship behavior among the individual. This will enable the organization to retain and engage their employees for a longer period of time.

Organizational citizenship behavior is directly linked with the organizational effectiveness which is being endorsed and attested by the different past researches. However; it is a new area of research that has attracted a large number of the researcher to focus upon this area for the purpose of improvement and bringing this culture to facilitate organizational effectiveness and performance adequately (Schappe, 2015). Hence leading to the following Hypotheses.

H3: Organizational citizenship behavior plays a significant role in organizational effectiveness.

H4: Organizational citizenship behavior plays a mediating role in the relationship between tangible rewards and organizational effectiveness.

H4: Organizational Citizenship Behaviour plays a mediating role in the relationship between intangible rewards and organizational effectiveness.

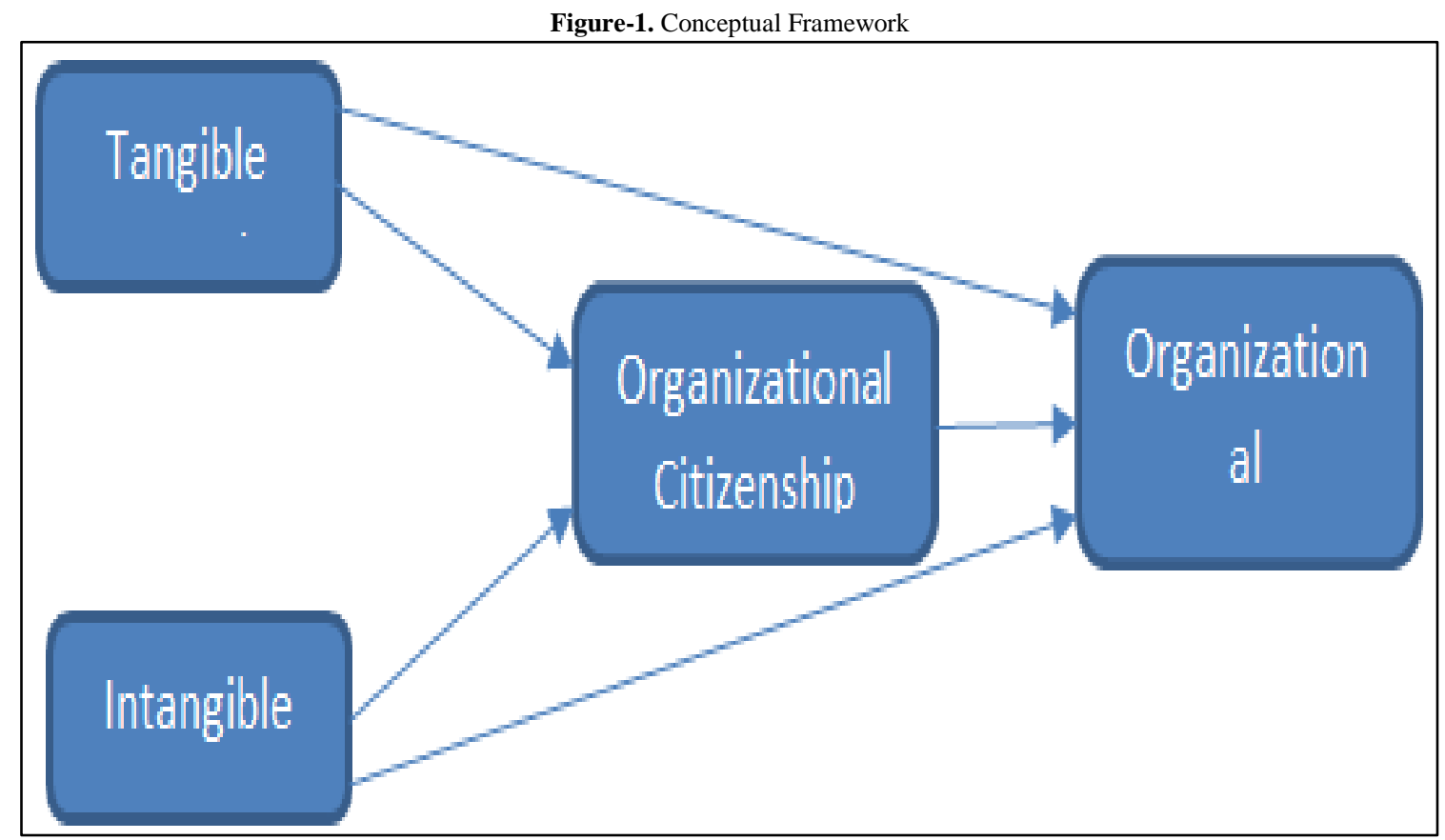

\section{Methodology}

The study utilized a quantitative research design for that the data was collected using a structured questionnaire. The questionnaire was initially distributed to 70 individuals and 52 questionnaires were returned. The pilot study was conducted using 52 filled questionnaire and for that purpose, exploratory factor analysis (EFA) was performed and the factor loading of each item was checked. The results of EFA showed the factor loading of each item to be greater than 0.7 on their respective constructs being acceptable and none of the items was removed from the questionnaire. In the next step, the questionnaire was sent to 550 individual out of that 349 questionnaires were returned however 342 of the questionnaires were found to be useable for the further data analysis and the rest 7 questionnaires were discarded. The study framework had 4 constructs namely tangible rewards, intangible rewards, organizational citizenship behavior and organizational effectiveness. Two of the variables (tangible and intangible rewards) were independent variables, organizational effectiveness was dependent variable and organizational citizenship behavior was mediating variables. All the latent construct was measured using multi items based on 5 point Likert scales from 1 strongly disagree to 5 strongly disagree. The data collection instrument was developed referring to past researches done on the seminal researches. The items used in each construct are tabulated in the table below along with the alpha value of construct reliability.

Partial Least Squares (PLS) structural equation modeling (SEM) were applied to estimate the measurement and structural model of this study using the software application SmartPLS 2.0. The results were presented in three steps. Firstly, the Harman single factor test was performed to test the existence of common method bias in the study. Secondly, the results of the measurement model were assessed and discussed. Thirdly, the results of hypothesis hypothesized in this study were assessed through the examination of the structural model.

For the assessment of direct and indirect relationships found in the study framework, Structural Equation Modelling was applied. For this SmartPLS 3 was used. However, before running the main data analysis on SPLS a data screening process was performed using Excel and SPSS. The data screening involved. Missing value and outliers detection, the normality of the data and checking for the unengaged responses. Thereafter a measurement model was estimated and based on the result of convergent validity including factor loading, average variance extracted (AVE), Composite reliability (CR) was examined. Furthermore, the discriminant validity was also examined based on the criteria by Hair et al. (2011). 
Table-1. Number of Items included in each construct

\begin{tabular}{l|l|l}
\hline Construct & Number of Items & Cronbach's Alpha \\
\hline Intangible Rewards & 4 & 0.83 \\
\hline Tangible Rewards & 4 & 0.74 \\
\hline Organizational Citizenship Behaviour & 3 & 0.93 \\
\hline Organizational Effectiveness & 4 & 0.73 \\
\hline
\end{tabular}

\section{Result and Analysis}

The first stage of the PLS-SEM was performed by estimating the measurement model. Results show that indicator loadings for all items exceeded the recommended value of 0.7 (Hair et al., 2009). The values for AVE ranged between 0.55 and 0.83 , hence exceeding the benchmark value of 0.5 and CR values ranged between 0.83 to 0.95 exceeding the benchmark value of 0.7 (Hair et al., 2009), see table 2. The measurement items' discriminant validity was examined following the criteria of Fornell and Larcker (1981), see table 3. The table shows the discriminant validity of the construct used in the model and shows that all values of AVEs present in the diagonal are higher than the off-diagonal values of inter-construct squared correlations.

The second stage of PLS-SEM (Path analysis) was performed to estimate the structural model. For this purpose, $\mathrm{R}^{2}$ and significance values of the path model were examined (Hair et al., 2011). The $\mathrm{R}^{2}$ for Organizational Citizenship Behaviour and Organizational Effectiveness were 0.23 and 0.53 respectively (see figure 2).

The hypotheses of the study show the relationship of tangible and intangible rewards with organizational effectiveness directly and through the mediation of organizational citizenship behavior. The results depicted that both tangible and intangible rewards (Tangible Rewards $\beta=0.21, \mathrm{p}<0.01$ and Intangible rewards $\beta=0.38, \mathrm{p}<0.00$ ) were significantly and positively related to the organizational Effectiveness while organizational citizenship behavior is also positively and significantly related to organizational effectiveness with $\beta=0.31, p<0.01$ (see table 4 ) for the direct effects.

Table-2. Results of Measurement Model

\begin{tabular}{|c|c|c|c|c|c|}
\hline Construct & Items & Loading & AVE & $\mathbf{C R}$ & Cronbach's Alpha \\
\hline \multirow[t]{4}{*}{ Intangible Rewards } & ITR1 & 0.83 & 0.67 & 0.89 & 0.83 \\
\hline & ITR2 & 0.84 & & & \\
\hline & ITR3 & 0.82 & & & \\
\hline & ITR4 & 0.77 & & & \\
\hline \multirow[t]{4}{*}{ Tangible Rewards } & TR1 & 0.82 & 0.56 & 0.83 & 0.74 \\
\hline & TR2 & 0.73 & & & \\
\hline & TR3 & 0.70 & & & \\
\hline & TR4 & 0.72 & & & \\
\hline \multirow{4}{*}{$\begin{array}{ll}\text { Organizational } & \text { Citizenship } \\
\text { Behavior } & \end{array}$} & OCB1 & 0.90 & 0.83 & 0.95 & 0.93 \\
\hline & OCB2 & 0.90 & & & \\
\hline & OCB3 & 0.93 & & & \\
\hline & OCB4 & 0.91 & & & \\
\hline \multirow[t]{4}{*}{ Organizational Effectiveness } & OE1 & 0.75 & 0.55 & 0.83 & 0.83 \\
\hline & OE2 & 0.74 & & & \\
\hline & OE3 & 0.77 & & & \\
\hline & OE4 & 0.71 & & & \\
\hline
\end{tabular}

Note: AVE = Average Variance Extracted, CR = Composite Reliability

Table-3. Discriminant Validity of Constructs

\begin{tabular}{|c|c|c|c|c|}
\hline & $\begin{array}{l}\text { Intangible } \\
\text { Rewards }\end{array}$ & $\begin{array}{l}\text { Tangible } \\
\text { Rewards }\end{array}$ & $\begin{array}{l}\text { Org Citizenship } \\
\text { Behavior }\end{array}$ & $\begin{array}{l}\text { Org } \\
\text { Effectiveness }\end{array}$ \\
\hline Intangible Rewards & 0.82 & & & \\
\hline Tangible Rewards & 0.42 & 0.75 & & \\
\hline $\begin{array}{l}\text { Organizational Citizenship } \\
\text { Behavior }\end{array}$ & 0.43 & 0.39 & 0.91 & \\
\hline $\begin{array}{l}\text { Organizational } \\
\text { Effectiveness }\end{array}$ & 0.61 & 0.49 & 0.56 & 0.74 \\
\hline
\end{tabular}

Table-4. Results of Direct Effects

\begin{tabular}{|c|c|c|c|}
\hline Hypotheses/Path & Path Coefficient & T Statistics & Decision \\
\hline H1: Tangible Rewards $\rightarrow$ Org Effectiveness & 0.21 & $4.76 * * *$ & Supported \\
\hline H2: Intangible Rewards $\rightarrow$ Org Effectiveness & 0.38 & $8.54 * * *$ & Supported \\
\hline H3: Org Citizenship Behavior $\rightarrow$ Org Effectiveness & 0.31 & $6.38 * * *$ & Supported \\
\hline
\end{tabular}


Mediating effect of Organizational Citizenship Behaviour in the relationship between (tangible and intangible rewards) and organizational effectiveness has been having been examined see table 5. Following Preacher and Hayes (2008) for testing mediation effect, the results show that the relationship of tangible rewards $t=4.52, \mathrm{p}<0.05$ and intangible rewards $\mathrm{t}=4.52, \mathrm{p}<0.05$ ) and organizational effectiveness is mediated by the organizational citizenship behavior.

Table-5. Results for Mediating Effects

\begin{tabular}{|c|c|c|c|}
\hline Hypotheses/Path & Path Coefficient & T Statistics & Decision \\
\hline $\mathrm{H} 4: \mathrm{TR} \rightarrow \mathrm{OCB} \rightarrow \mathrm{OE}$ & 0.08 & $4.16 * * *$ & 0.00 \\
\hline H5: ITR $\rightarrow$ OCB $\rightarrow$ OE & 0.10 & $4.52 * * *$ & 0.00 \\
\hline
\end{tabular}

Figure-2. Structural Model

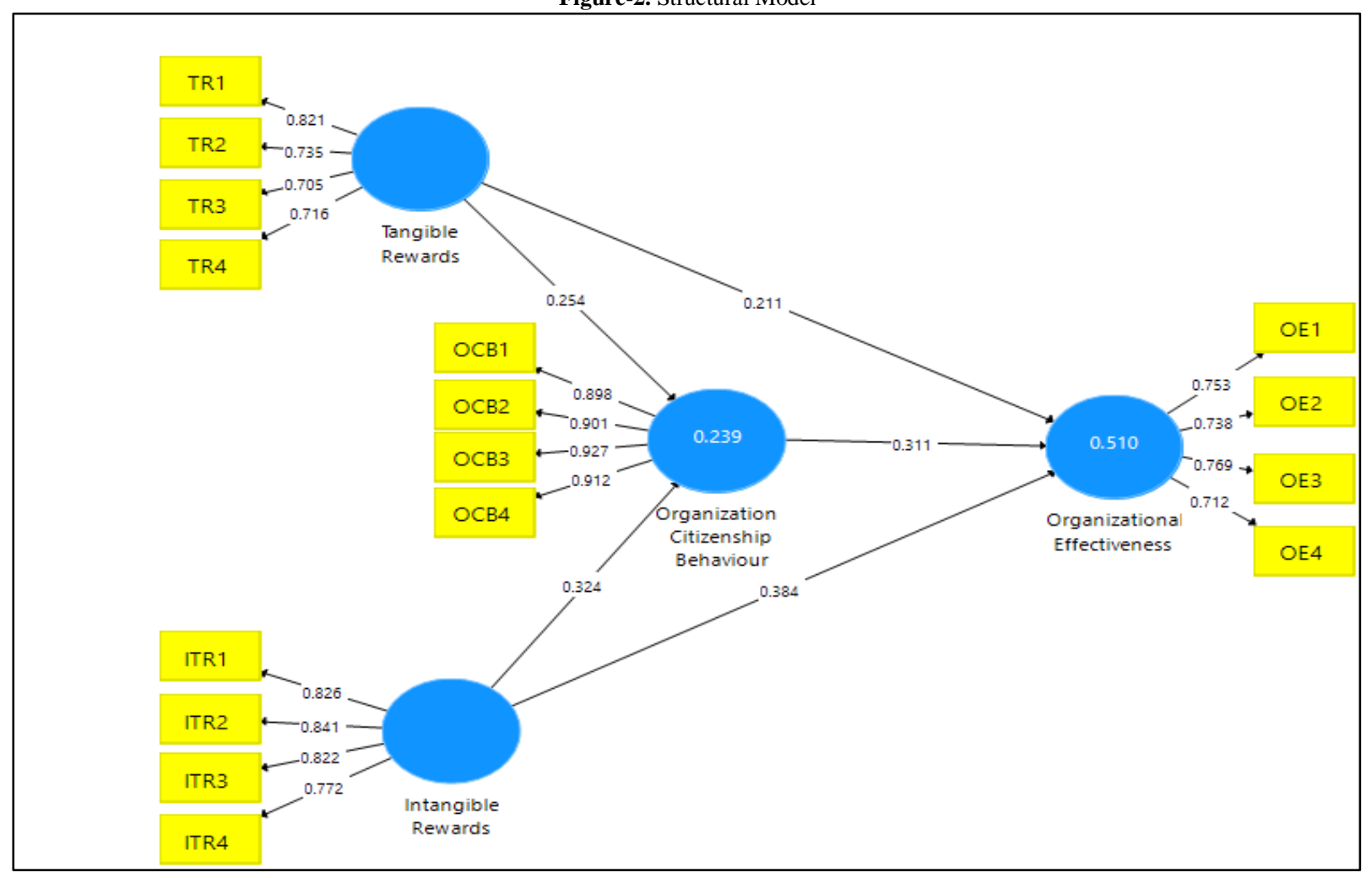

\section{Discussion}

The article aimed to examine the impact of tangible and intangible rewards on organizational effectiveness directly and through the mediation of organizational citizenship behavior. The results suggested the significant relationship of tangible and intangible rewards with organizational effectiveness directly and through the mediation of organizational citizenship behavior. Hence indicating that tangible and intangible rewards play a vital role in organizational effectiveness and organizational citizenship behavior has an important intervening role between these relationships.

The rewards are associated with the motivational theories that assess the individual requirement regarding the rewards. It is important that currently, every organization is focusing upon the development of criteria whether they want to lead in the market or follow the pattern of the market. Most of the organizations become efficient and effective as well in order to utilize their resources efficiently and enable their resources to help them for achieving the desired objectives (Kwenin et al., 2017). As the human resource is one of the key resources for any organization to keep them motivated towards their work they have to be compensated in the form of tangible and intangible rewards. Rewards are designed in order to meet the employee's expectations and appreciate the effort they put in the attainment of organizational objectives. However; it is highly effective for the employees to get appreciated and rewards are being distributed on the basis of their performance. The organization should link their reward system with the organizational strategies that will become the most effective standard for assigning the rewards to the employees and in this way, it will increase the performance and effectiveness of the organization considerably (Edirisooriyaa, 2015). It is required that organization should consider the employees are the main source of generating the effectiveness and financial profitability because they are the mainstream that faces the challenges and enable the organization to achieve their objectives considerably (Omollo and Oloko, 2015). Tangible rewards are being used at a certain level for the employees to increase their motivation and loyalty as well, however; it is difficult to say that tangible rewards are directly linked with organizational effectiveness. It can be suggested that organizational effectiveness is having a certain relation with the tangible rewards that offer to the employees on the 
basis of their performance and somehow it is effective to meet the organizational objectives and contribute towards the organizational effectiveness (Yousaf et al., 2015). Hence the results regarding the relationship of tangible rewards and organizational effectiveness are in line with the literature.

It is evident that higher management seeks to get the intangible rewards which increase their influence and powers adequately (Day et al., 2016), however; middle management considers that the combination of tangible and intangible rewards the best way to increase their motivation; but top management is being facilitated through the intangible rewards and enable them to take decision for the future of organization. Similarly; this feature is also associated with the enhancement of the employee's performance and efficiency (Terera and Ngirande, 2014).

Organizational effectiveness is also linked with the intangible rewards that are being offered to the employees but it is an appreciation in regards of the employee's commitment and dedication towards the attainment of objectives (Omollo and Oloko, 2015). Research suggests most of the employees prefer to get the intangible rewards to increase their motivation. Hence the finding of the study regarding a significant relationship intangible rewards and organizational effectiveness are aligned with the above discussion of the past literature.

Citizenship in the organization is based upon the commitment and dedication of the employees towards the organizational objectives and performance. Therefore; it provides the luxury to bring efficiency and effectiveness which is quite adequate and simple but it should be given strength to the employees to facilitate this behavior (Schappe, 2015). However; it is evident that those employees those are having citizenship behavior they are loyal and dedicated towards their jobs and attainment of objectives that are assigned to them considerably. It is indeed necessary that the organization should provide a legitimate environment and culture to promote the working environment (Carrdona and Bentler, 2016). Organizational citizenship behavior is directly linked with the organizational effectiveness which is being endorsed and attested by the different past researches. However; it is a new area of research that has attracted a large number of the researcher to focus upon this area for the purpose of improvement and bringing this culture to facilitate organizational effectiveness and performance adequately (Schappe, 2015). The study finding regarding the H3, H4, and H5 are also aligned with the above literature, hence showing the significant impact of organizational citizenship behavior on organizational effectiveness. Moreover, Organizational effectiveness plays a significant mediating role in the relationship of tangible and intangible rewards with organizational effectiveness.

\section{Managerial Implication of the Research}

As the managerial implication of the current work, it is suggested that the Iraqi organizations should concentrate on the on the rewards given to their employees against their performance as the study findings suggest the significant role of intangible and tangible rewards in organizational effectiveness. Moreover, the significant mediating role of organizational citizenship behavior suggests that organizations need to improve employee's organizational citizenship behavior and articulate such HR policies that motivate employees more towards their work and their organization.

\section{Limitation and Future Research}

The current work has few limitations as the data was only taken from the Baghdad region of Iraq, not the other cities. It is important to take the data from the other cities of Iraq to generalize the results for the whole Iraqi context. Moreover, the framework of the study only covers the tangible and intangible rewards and not the other compensation such as bonuses etc. The study focused on the organizational effectiveness in future researchers can enhance the model and bring in more variables such as organizational survivability, innovativeness, productivity etc. The methodology of the study is limited to quantitative design for an in-depth understanding of the phenomena qualitative data may be helpful for the researcher or a more novel methodology of mixed design would be more suitable for more insight into the topic.

\section{References}

Abdelqader, A. A. A., Chao, H. S., Mohammad Eneizan, B. and AL-kharabsheh, K. A. (2018). Explore the relationship between human resource management practices and the consequences for emotional labor of insurance agents in the Jordanian insurance industry. Cogent Business and Management, 5(1): 1445407.

Alsakarneh, A. A. A., Hong, S. C., Eneizan, B. M. and AL-kharabsheh, K. A. (2018). Exploring the relationship between the emotional labor and performance in the Jordanian insurance industry. Current Psychology: 112.

Available: https://www.researchgate.net/publication/326656993_Exploring_the_relationship_between_the_emotional_ labor_and_performance_in_the_Jordanian_insurance_industry

Antoni, C. H., Baeten, X., Perkins, S. J., Shaw, J. D. and Vartiainen, M. (2017). Reward management: Linking employee motivation and organizational performance. Journal of Personnel Psychology, 16(2): 57-60.

Carrdona, L. B. and Bentler, P. (2016). The influence of social and work exchange relationships on organizational citizenship behavior. Group and Organizational Management, 29(2): 219-47.

Day, J. W., Holladay, C. L., Johnson, S. K. and Barron, L. G. (2016). Organizational rewards: considering employee need in allocation. Academic Search Complete, EBSCO host. Personnel Review, 43(1): 74-95.

Edirisooriyaa, W. A., 2015. "Impact of Rewards on Employee Performance: With Special Reference to ElectriCo." In Proceedings of the 3rd International Conference on Management and Economics. p. 27. 
Fornell, C. and Larcker, D. F. (1981). Evaluating structural equation models with unobservable variables and measurement error. Journal of Marketing Research, 18(1): 39-50. Available: http://dx.doi.org/10.2307/3151312

Hair, J. F., Ringle, C. M. and Sarstedt, M. (2011). PLS-SEM: Indeed a silver bullet. The Journal of Marketing Theory and Practice, 19(2): 139-52. Available: http://dx.doi.org/10.2753/MTP1069-6679190202

Hair, J. F., Black, W. C., Babin, B. J. and Anderson, R. E. (2009). Multivariate Data Analysis. Pearson Prentice Hall: Upper Saddle, New Jersey.

Hall-Ellis, D. S. (2014). Reward systems promote high-performance work teams achieving library mission. Academic Search Complete, EBSCO host. The Bottom Line, Managing Library Finances, 27(2): 66- 69.

Kwenin, D. O., Muathe, S. and Nzulwa, R. (2017). The influence of employee rewards, human resource policies and job satisfaction on the retention of employees in Vodafone Ghana Limited. European Journal of Business and Management, 5(12): 13-20. Available: http://www.iiste.org/Journals/index

Obaid, T. F. and Eneizan, B. M. (2016a). The mediating of training transfer between pre training factors and job performance. Review of Public Administration and Management, 400(3786): 1-11.

Obaid, T. F. and Eneizan, B. M. (2016b). Transfer of training and post-training on job performance in Middle Eastern countries. Review of Public Administration and Management, 400(3786): 1-11.

Omollo, P. A. and Oloko, M. A. (2015). Effect of motivation on employee performance of commercial banks in Kenya: A case study of Kenya Commercial Bank in Migori County. International Journal of Human Resource Studies, 5(2): 87-103. Available: https://doi.org/10.5296/ijhrs.v5i2.7504

Pratheepkanth, P. (2016). Reward system and its impact on employee motivation in commercial bank of Sri Lanka Plc, In Jaffna District. Global Journal of Management and Business Research, 11(4): 85-92.

Preacher, K. J. and Hayes, A. F. (2008). Asymptotic and resampling strategies for assessing and comparing indirect effects in multiple mediator models. Behavior Research Methods, 40(3): 879-91.

Sanhari, M. S. (2014). Relationship between employee engagement and performance: A case study of health workers in Tanzania. International Journal of Engineering and Management Science, 5(3): 215-19. Available: http://connection.ebscohost.com/c/articles/97243510/relationship-betweenemployee-engagementperformance-case-study-health-workers-tanzania

Schappe (2015). The influence of job satisfaction, organizational commitment and fairness perceptions on organizational citizenship behavior. Journal of Psychology, 132(3): 227-90.

Sharif, Z. M., Obaid, T. F., Eneizan, B. M. and Abumandil, M. S. S. (2018). Determine process training key factors and job performance in higher education sector. International Journal of Engineering and Technology, 7(4.15): 477-80.

Terera, S. R. and Ngirande, H. (2014). The impact of rewards on job satisfaction and employee retention. Mediterranean Journal of Social Sciences, 5(1): 481-87. Available: https://doi.org/10.5901/mjss.2014.v5n1p481

Tsede, O. A. and Kutin, E. (2015). Total reward concept: A key motivational tool for corporate Ghana. Business and Economic Research, 3(2): 173-82. Available: https://doi.org/10.5296/ber.v3i2.4291

Yousaf, A., Huadong, Y. and Saunders, K. (2015). Effects of intrinsic and extrinsic motivation on task and contextual performance of Pakistani professionals. Academic Search Complete, EBSCO host. Journal of Managerial Psychology, 30(2): 133-50. 